\title{
Castrejón, Cóccioli y Novo: La novela gay en la primera mitad del siglo XX
}

\author{
Antonio Marquet \\ Universidad Autónoma Metropolitana-Azcapotzalco
}

Tratar de las tres primeras novelas que en México abordan la homosexualidad de la primera mitad del siglo xx es un acto artificioso. Ciertamente las obras fueron escritas en la primera mitad del siglo XX. Sin embargo, al colocar esos tres momentos de escritura dentro de un periodo para su estudio, se podría esperar que implícitamente entrarían en una dinámica consecutiva. En realidad, cada uno de esos momentos estuvo aislado.

¿Novo leyó a Castrejón? Seguramente. En cambio, Carlo Cóccioli (1920-2003) ciertamente no leyó a Eduardo Castrejón ni a Salvador Novo (1904-1974) antes de escribir su Fabrizio Lupo (1952). Significa una violencia, incluso una especie de mentira deliberada, el hecho de examinarlos como una unidad temporal. La novela de Castrejón fue impresa en el ocaso del orden porfirista; la de Novo, concebida en la ebullición de una nueva cultura mexicana; ${ }^{1}$ la de Cóccioli, escrita en Italia, antes de que el autor decidiera asentar su domicilio en México. ${ }^{2}$

1 Algunas fechas importantes en la cronología de La estatua de sal son: el 15 de octubre de 1945 (406), empieza Novo a hablar en sus artículos periodísticos de su autobiografía; en 1979, los Cuadernos del Frente homosexual de Acción revolucionaria publican un fragmento; en 1980 Nuestro cuerpo, frente de acción revolucionaria y además la revista Proceso publican otro fragmento. En 1998, Conaculta publica la edición íntegra.

${ }^{2}$ Habría que señalar además que fue escrita en francés y que después de la publicación Carlo Cóccioli tuvo que cambiar de domicilio y de continente: la homofobia en aquella época no era un asunto que pudiera discutirse. En cuanto a las vicisitudes de publicación de la novela de Novo, son elocuentes también de la homofobia. Medio 
Si la primera obra es producto de un escritor mediocre, oportunista y debe considerarse como un pésimo ejercicio político y una negra página en la historia de los derechos humanos, las de Novo y Cóccioli son novelas escritas con las entrañas. A este respecto habría que recordar las numerosas referencias de Novo al conflicto emocional que implicó La estatua de sal. ${ }^{3}$

La homosexualidad es un asunto subordinado, narrativa y axiológicamente en Los cuarenta y uno: novela crítico social (1906), a pesar del título de la novela. Para abordar semejante tema, Castrejón se vale de un

siglo fue necesario para que apareciera como libro (1945 a 1998 según los datos de la nota anterior).

3 Tomo algunas referencias de la obra de Rosa María Acero:

Mientras avanzo en escribir los penosos, iniciales capítulos de La estatua de sal, revivo los recuerdos de aquella patria chica en que transcurrió mi niñez. Desde entonces, nunca la he visitado y seguramente tiene parte en ello mi subconsciente que retiene vivas aún las últimas impresiones recibidas allá, desagradables, crueles algunas, todas definitivas en la escultura final (546).

Conforme reconstruyo situaciones y personajes descubro en ellos rasgos, raíces, estereotipos, que no había percibido nunca antes con igual claridad. Llegamos ya a Torreón, y los bocetos trazados en Return ticket, con todas las inhibiciones que entonces les impuse, reclaman ahora un tratamiento nuevo y más amplio. Pero ¿mejor? (535).

Me falta mucho; no puedo saber cuántas páginas, para concluir la exhumación minuciosa de una infancia que me atrae tanto como me angustia y me daña resucitar (564-565).

Con una nerviosidad inexplicable... y sin más ni más, las comencé, por los recuerdos más remotos de mi infancia. Mi primera imagen propia data de mis cuatro años de edad. Con inusitada soltura, llené cuartilla tras cuartilla, hasta depositarme en Chihuahua, a los siete años (406).

Y de repente, me asalta este pensamiento desolador. La complacencia sádica, a la vez masoquista, con que desnudo y acuso, analizo y expongo al niño neurótico y extraviado que pintan estas páginas, ¿no equivale a la vigilancia atenta que, de tener un hijo, consagraría a su educación? ¿No estoy creando lo que no he podido engendrar, en mí mismo? (564-565).

Llevo unos días de plantearme la elección final entre tres maneras de volcar mi experiencia y ejercitar mi desarrollada aptitud en una obra literaria para cuya ejecución he empezado a rodearme física y espiritualmente [...] si en la novela que tengo bien planeada [...] en una serie de Never Told Tales [...] o en unas Memorias que usarían exactamente el mismo material autobiográfico (503). 
pretexto y utiliza como coartada propósitos proselitistas: pretende demostrar el grado de decadencia de la aristocracia para la clase obrera. En el horizonte ético de Castrejón nada puede ser peor que la homosexualidad.

Los cuarenta y uno se estructura como un armazón publicitario cuya inflamada voluntad de condenar y moralizar delata una sed de reafirmación en el campo del poder discursivo. La moral en cuestión se satisface en el castigo de los desviantes. El narrador travestido en verdugo, un ser políticamente bien pensante, no se avergüenza de mostrar su capucha tras sus aspavientos de horror (ni el inquisidor ni el verdugo dudan por un momento de encontrarse en el error). La fobia sustituye a la argumentación y a la razón. La maquinaria narrativa se pone al servicio de prejuicios para abortar una novela complaciente que daría pábulo al morbo de un público ávido de detalles obscenos (tal es el respeto que muestra este socialista por los obreros). Atrapado en sus propios prejuicios, Castrejón ni siquiera cumple con las expectativas de una noveleta obscena. Se limita a aludir a escenas calificadas de escalofriantes sin proporcionar detalles. Su novela parte de los hechos sabidos por el público. El incidente de la Calle de la Paz que movía a la risa, al albur; eso que en la sociedad era un festín humorista, con Castrejón adquiere tintes sombríos; tiene la seriedad y la seguridad inquisitoriales.

Más que la homosexualidad importan los semblantes de valores que se repite un grupo político que se siente civilizado, poseedor de la Verdad social. Contrariamente a lo que se esperaría, Castrejón no se atreve a atacar directamente a su adversario real, el sistema porfirista, enemigo de los obreros. Procede de manera sesgada: adjudica crímenes a la aristocracia y nada le parece más fácil para concitar la unanimidad de los lectores que la homosexualidad. Aunque no le importe mayormente, hay que sacrificar al homosexual, es sangre barata, nadie meterá las manos en su defensa.

No es el momento de la crítica social, ni de la afirmación de una ideología. El narrador oportunista tampoco tiene los aprestos ni la capacidad para hacerlo. Castrejón permite observar la cobardía ideológica de una izquierda timorata de principios del siglo pasado que lo único que supo y pudo fue envolverse con la toga de la virtud: deplorable forma de travestismo ideológico que se sigue repitiendo en una Asamblea de Representantes que ha postergado la ley de uniones solidarias simplemente por un frío cálculo político. 
Hasta en Fabrizio Lupo, la estructura narrativa padece de una cierta insuficiencia. La estatua de sal tiene dos momentos de narración: uno en el que el sujeto rememora su infancia, en que aparece solo, aislado, a merced de una madre que se planta como una voluntad de contrariar y una segunda parte en que Novo, consciente de su talento y belleza, ejerce el poder de la palabra como articulista y también como difamador. $L a$ estatua de sal es una novela fragmentaria, elaborada a base de anécdotas dotadas de un manifiesto objetivo de escandalizar (hay que tomar en cuenta que la modernidad, que en las artes significaba el surrealismo, preconizaba el escándalo. Luis Buñuel quizá sea el otro ejemplo acabado de los poderes del escándalo en el contexto mexicano). El narrador yuxtapone viñetas que aluden a una vida sexual tumultuosa. En su autobiografía, no hay un final, sino la última anécdota que cuenta. Novo crea un engaste narrativo al que se le podrían añadir innumerables escenas. La estatua de sal es un proyecto al mismo tiempo volcánico e interrumpido. El vigor y la violencia que cobra la palabra de Novo en esta novela es sin duda el mayor terremoto que haya registrado la literatura mexicana en cuanto a liberalización, con el concomitante fracaso de las estrategias de represión, tan secular y laboriosamente armadas. Novo inventó espacios que nunca antes habían sido explorados por la literatura mexicana, ni universal. En efecto, el espectro emocional que recorre La estatua de sal comprende tanto la melancolía, como el acta de acusación, la denuncia, ${ }^{4}$ la burla, el cinismo, el palpitar de placer, el goce transgresivo, el exhibicionismo, el masoquismo moral, la ausencia de solidaridad con homosexuales a los que exhibe...

En cuanto a Fabrizio Lupo, la novela se divide en tres partes. En la primera y en la tercera interviene un novelista que se coloca como una

\footnotetext{
${ }^{4}$ Novo exhibe a la gente con el cálculo minucioso de señalar nombre y apellidos: Al Sr. Aristi le dicen la nalga que aprieta; al Lic. Solórzano, la Tamales (porque invitaba tamales y chocolate); de Martell se dice que paga mil pesos a un torero por sus favores; a Enrique Mendoza Albarrán, le dicen la Suzuki; Novo habla de La Madre Meza, Sor Demonio, del padre Vallejo Macouzet; señala que Luis Amieva no tiene erección; que Carlos Gutiérrez Palacios es el amante que lo descubre con los choferes; que Augusto Fink tiene una verga descomunal y es amante de Nacho Moctezuma. ¿Hay que preguntarse cómo leerían estas personas sus nombres en tal biografía? ¿serían capaces de apreciar las cualidades estilísticas de este libro? Sin duda Novo tenía un lado oscuro, odioso, temible para sus amigos y compañeros, que nosotros al gozar de La estatua de sal no podemos imaginar siquiera.
} 
instancia que puede juzgar literariamente, humanamente una vida: es decir con objetividad. Es a él a quien entrega su manuscrito el pintor: el novelista estará encargado de transmitir su testimonio, exponer su "caso", a la sociedad y a la posteridad. El clóset se abre y aparece la voluntad de manifestarse con premura; de exponer a fondo, de dar a conocer algo insólito: una vida homosexual que es relatada por un homosexual: es preciso señalar que el escritor que funciona como interlocutor del pintor, no hace sino transcribir detalladamente los encuentros y que su capacidad fabuladora se limita a testimoniar y a cumplir con la última voluntad de un suicida. A diferencia de Novo, su propósito no es escandalizar, sino transmitir un mensaje en el que se defiende un caso y se elabora un acta de acusación contra una sociedad que no permite el amor entre homosexuales. Según las afirmaciones del pintor transmitidas por el escritor, la sociedad tolera la homosexualidad episódica, mas no la constitución de una pareja (el mismo fenómeno se puede admitir en la actualidad en la que se ha echado atrás la posibilidad de las uniones gay; aún no se ha discutido en cámaras). En cuanto al escritor tan sólo es el garante de que esa experiencia homosexual se difunda: Fabrizio acude al escritor como una instancia simbólica social, ¿podría cumplir esta función de difusión otra profesión, un abogado, un sacerdote, un médico, un sociólogo? Sintomáticamente el pintor no recurre a ellos.

El tono, la fuerza y ritmo de la primera y tercera parte, compuestas por entrevistas o cartas, es más directo, más fuerte. El capítulo central es menos logrado: el pintor pasa de lo particular a un mundo abstracto. Quiere transformar a sus múltiples partenaires en la representación de su ideal y de sus aspiraciones amorosas: la pluralidad es reducida a la singularidad representativa. Si Novo se complace en exhibir con pelos y señales, dando nombre y apellidos de las personalidades a las que balconea, Cóccioli prefiere desdibujar el rostro de los partenaires de Fabrizio, convertirlos en un símbolo, los reúne dentro de una entelequia (coquetería que ahora parece fuera de lugar). Ciertamente se trata de una estrategia expositiva cuyo significado argumentativo y moral resulta claro: al mismo tiempo que se protege contra la acusación de promiscuidad (antivalor por antonomasia de una moral basada en el matrimonio-monogámico), por medio de esta condensación se nombra a la curiosidad sexual de Fabrizio, una unidad significante que resulta difícil de creer para un lector contemporáneo. 
Fabrizio Lupo aboga por una nueva homosexualidad. La novela establece quiénes son los enemigos (la sociedad heterosexual —en particular la moral católica-, y la misma comunidad homosexual de la época) y lucha contra las fuerzas que le impiden constituirse como una pareja: Si Lorenzo no se permite asumir su homosexualidad y opta por el suicidio se debe a la homofobia que se manifiesta en la sociedad homosexual que desea participar comunitariamente en el festín del nuevo catecúmeno; los confesores que permiten el ciclo promiscuidad-confesión-arrepentimiento, pero no conceden la absolución a los amantes; la familia que presenta a Lorenzo prospectos de prometidas...

Los ingredientes de la primera novela que aborda la homosexualidad, Los cuarenta y uno es la exhibición lacerante del homosexual, la burla por la diferencia, el castigo acérrimo y la moraleja en una sociedad hipócrita; Novo opta en cambio por el auto-balconeo, y por entregarse a una vida sexual desbordante tras un camino de inseguridad. Es seguro que a él no lo podrán acusar ni exhibir porque en ese camino él les ha ganado la partida yendo hasta lo inimaginable, hasta aquello que el mojigato socialista ni siquiera puede nombrar. Con Cóccioli es el propio homosexual el que se abre al público, pero establece previamente las coordenadas de comprensión en que esa salida del closet se realiza. Sus tácticas dejan claro que no quiere ser descalificado con una injuria, pretende que la sociedad vaya más allá superando sus propias repugnancias, y que conozca su intento desesperado por establecer una pareja, el fracaso y el suicidio. Fabrizio Lupo expresa su última voluntad que radica en que todos sepan que no merece la pena una vida sin el amor homosexual.

La condena virulenta de Castrejón, la voluntad de escandalizar de Novo y una voluntad suicida de Cóccioli, articularían la lógica de los modos de representación discursiva de la homosexualidad en la primera parte del siglo Xx. Para hablar de la homosexualidad parecería que es preciso adoptar una postura extremista, radical: Castrejón la utiliza dentro de un sólido cerco moral; Novo la expresa para escandalizar, con una actitud tan desafiante como defensiva; Cóccioli coloca a una pareja homosexual en el amplio contexto de la imposibilidad amorosa que priva en el mundo afectivo de la posguerra.

Las tres primeras novelas aparecen sin formar un entramado que las aglutine, sin un tejido social que permita que se les reconozca como unidad significativa: la de un grupo, colectivo o comunidad en busca 
de expresión (para ello habrá que esperar hasta la publicación del célebre artículo iniciador de Luis Mario Schneider (1931-1999), "El tema homosexual en la nueva narrativa mexicana”). No se les puede hermanar a estos tres primeros autores. Aparecen aisladamente. Lo que media entre ellos es un mar proceloso de homofobia, una represión enorme. Entre el castigo y la provocación, entre el silencio amordazado y el suicidio navegó la novela homosexual de la primera mitad del siglo pasado.

Navegó en una situación paradójica, sobre todo si se tienen en cuenta las manifestaciones culturales gay que se dan en la poesía, en la pintura, en la danza, en el teatro y que están animadas por otras fuerzas que no son exclusivamente la tristeza, la soledad, la injuria, la acusación, la criminalidad. Es ajena al exuberante colorido de la primera pintura homosexual, de esa fuerza que conduce a los pintores a trazar el retrato de la comunidad y de dar a aquellos a los que la sociedad apunta con su rígido dedo de desprecio, el espacio simbólico de un retrato con las connotaciones de respetabilidad y celebridad que el retratado tiene en la sociedad de la primera mitad de siglo una pinacoteca gay. La puesta en novela de la homosexualidad no conoce el espacio de consagración que significa el retrato, ${ }^{5}$ donde el retratado es un ser observado por una mirada que proyecta para la posteridad, y que lleva al modelo a la pared de la estancia: si acaso la novela se refocila en la grotesca caricaturización, traza un autorretrato melancolizado.

La celebración del cuerpo desnudo de San Sebastián o las contorsiones de un cuerpo gay amanerado en la pintura de Abraham Angel, los dioses de Saturnino Herrán, hablan con un colorido festivo de una celebración. Crean espacios cálidos. Montenegro retrata a Novo en bata en un taxi, con un espíritu ciertamente de burla y balconeo, pero también con el gozo de compartir un lenguaje y un código que solo los catecúmenos comprenden; para delatar sus inclinaciones por los taxistas, se habla ya de esas preferencias en un espacio público, la ambigüedad permite espacios de secreto y de balconeo. Los homosexuales saben la burla; los heterosexuales pasan sin advertir el chascarrillo. Ante el cuadro, la comunidad se reconoce por el entendimiento, porque puede

\footnotetext{
${ }^{5}$ Roberto Montenegro (1885-1968) conocido por su "Mateo el negro (pescador de Mallorca)" y "Desnudo" de 1913; elabora retratos de Elías Nandino, Salvador Novo o Chucho Reyes Ferreira, primera galería de gays.
} 
captar el sentido, porque puede reír y gozar de que el sentido de su atrevimiento no resulte inteligible a los legos. Desde esta perspectiva, la obra crea, pone en evidencia, alienta la existencia de la comunidad.

Las tres primeras novelas tampoco tienen nada que ver con los presupuestos teatrales de El tercer Fausto (1934) de Salvador Novo donde la unión amorosa homosexual se desvanece por el deseo del protagonista de cambiar de sexo, y de esta forma de normalizar su unión amorosa. Sin embargo, no es necesario vender el alma al diablo para gozar del amor homosexual, nos dice Novo. Los miembros de la comunidad deben aprender a reconocer que son amados tal como son; hay que saber leer esa dimensión afectiva y asumirlo, sin dejarse llevar por la fuerza de los valores heteronormativos introyectados. Como la trama lo demuestra, lo imposible, es decir la unión amorosa homosexual, es un obstáculo imaginario que el sujeto mismo se impone. El homosexual tiene que ser realista y reconocer el amor que se le profesa en el entorno. Al enunciar esta trama en el contexto de la novela que es sin duda un universo menos permisivo, parecería que al poner en escena el amor entre dos homosexuales se está hablando de un cuento de hadas.

Parecería que las tres primeras novelas gay nada tienen que ver con el lirismo de los nocturnos de Villaurrutia, con las declaraciones programáticas de Luis Cernuda... Y sin embargo esa primera novela es el complemento del colorido celebratorio de la pintura gay, del lirismo y de las proclamas poéticas del momento: esta faz radiante de las artes de la representación, tiene un envés sombrío: el de una vida sin horizontes, el de una tensión social, el de la fuerza del amordazamiento.

\section{LA ESTATUA DE SAL}

Entro a la biografía de Novo por el personaje que considero más importante: Amalia López. Hija menor de una familia con nueve hijos, la madre de Novo es un ser excepcional. Marcada con un particular egoísmo, lo menos que puede decirse de ella es que no respalda las múltiples empresas de su esposo, un hombre particularmente débil. Su egocentrismo la lleva a recluirse en sus habitaciones, mientras deja a su esposo luchar solo con las dificultades de iniciar una y otra vez una nueva vida, una y otra vez en diferentes sitios, diferentes oficios, tan sólo para sumar fracasos, hasta que sale a morir solo en Torreón 
de donde llega la noticia de su fallecimiento, de tisis, Novo es condenado por la madre al ostracismo. Según el testimonio del autor, la madre esperaba que por tener quince años, ella tenía que recibir todo de un hombre de treinta años, bien parecido, de ojos verdes (curiosa manera de acusar su "falta de solidaridad").

El egoísmo de la madre frente a su esposo se mezcla con una verdadera pasión por destruir al otro: al esposo de manera pasiva, calculada; al hijo de manera activa, sistemática, perversa. En efecto, Amalia López se vuelca con frenesí sobre su hijo. Ciertamente no es por amor; sino por una voluntad de forzar, de violentar la naturaleza del niño. En sus manos, Novo es un muñeco con el que puede entregarse a juegos perversos, como vestirlo de niña, impedirle que crezca, ponerle zapatos más pequeños que su pie; obligarlo a que frunza la boca, enseñarle un vocabulario disparatado en el que ano correspondía a pene. De una manera perversa, Novo se convierte en el espacio privilegiado donde se tramita decepción, fracaso, frustración y se administra el intercambio de violencia entre sus padres. En el niño inerme, Amalia muestra lo que el esposo es para ella. Un juguete, alguien sin autoridad. La prueba extrema de esa falta de carácter paterno es que permite que le hagan a su hijo cualquier cosa, le impongan humillaciones simbólicas y físicas. La violencia que Amalia ejerce con el niño Novo está dirigida al padre. Amelia aparece como un ser particularmente desestabilizador, funesto. $\mathrm{Su}$ perfil provoca malestar, repugnancia en el lector. Tras sus acciones se perciben los interminables reproches a un esposo que no es el héroe que ella quisiera, el superhombre que todo le solucionaría.

Cuando denuncia a su hijo para que sea castigado, Amelia no dice la verdad: que son afeminados; sino que Salvador se quiere ir con una compañía teatral infantil. Si el afeminamiento del niño no se puede decir, no puede ser asumido por la madre, hay en cambio, un castigo que debe cumplirse: la razón se inventa: es tan imprevisto, tan extremo el crimen que no puede ni siquiera reconocerse. En una comunicación particularmente reprimida, se desvían las transgresiones hasta el punto de ya no poder siquiera señalar su naturaleza.

En este lenguaje indirecto, contradictorio, disparatado, timorato de la madre ¿acaso no puede rastrearse la semilla, como reacción de vida, de la constitución de una palabra directa y descarnada del hijo? Contra esa insidia, ¿no prefiere Novo decir incluso lo peor (de sí, de los otros) a toda costa? Los niños dicen festiva, directamente: "Somos 
los dos afeminados de Torreón"; quizá sea lo más perturbador, que se expresen sin culpa y espontáneamente lo que no sólo debía permanecer callado, sino nunca haber sucedido.

Sin embargo, la reacción de Novo es sorprendente. En vez de rechazar a su madre, de mostrar su resentimiento, quiere identificarse con ella, ser como ella (quizá de tal manera pueda sobrevivir). Para lograrlo, Novo se traviste con las indumentarias de la madre. Su objetivo es tomar el sitio de la madre ya sea a través de portar sus atavíos, ya sea a través de adoptar su postura como madre lactante y pródiga e iniciar su vida sexual con un niño que debe chupar su pezón. Si ambiciona el sitio de la madre es para corregirle la plana al destino y realizar lo que ella debió haber hecho: llevar una vida sexual, es decir responder al deseo erótico y no ceder al deseo de ser admirada y de destruir; y ofrecer al niño protección y amor materno.

Los aliados de la madre se multiplicaron en la vida de Novo. La homofobia toma la forma de profesores sádicos, autoritarios, que quieren humillarlo y que confabulan a los alumnos contra él. Se establecen las primeras formas de la paradoja, quien trasmite el saber se convierte en el perseguidor.

Frente a la morosidad de los primeros recuerdos de La estatua de sal, pronto el relato se constituye como una sucesión de breves escenas, rápidas, inesperadas, clandestinas, de intimidad. La vida sucede, sigue su rumbo, en esas escenas en que intervienen dos, se dan besos, se producen las primeras eyaculaciones, los primeros intentos sexuales ya sea de penetración o de fellatio. La biografía, lo contable, lo que individualiza son estos momentos robados. Se trata de una historia fragmentaria, clandestina, de la constitución de una sexualidad. Todo lo dice el narrador sin ambages, descarnadamente, incluso aquello que puede parecer más perturbador. Lo importante es trazar el perfil del goce, el extrañamiento de un niño que se va descubriendo al azar el goce y al mismo tiempo conoce el efecto liberador de decir directamente. Mientras la inseguridad se establece en la vida pública y la vida camina con interrupciones, con irrupción de la violencia, con el terror de la sociedad, se traza y se instala segura una pulsión marginante.

La relación de Novo con la ciudad de México es la de un amor a primera vista que no hace sino crecer: "Todo el lujo, todas las excelencias de esta ciudad, me provocaban a un disfrute inmediato" (78); después de su retorno a la ciudad de México Novo es sensible a la moda, 
a los paseos, a los dulces. La ciudad de México le entra por los sentidos como una fiesta. La estatua de sal deja el testimonio de una ciudad que ya no existe, de una ciudad que ha sido sistemáticamente destruida. "Entre la escuela y la casa, se extendía, larga, la seductora, desconocida, ciudad, convocándome a recorrerla, a sentir en ella el disfrute de mi inédita libertad" (76). Al mismo tiempo es el aprendizaje del rechazo y de la instauración de una "escapista voluntad de ruina":

Y una tarde, Guillermo regresó a casa con huellas evidentes de haber reñido. Por la noche, como dormíamos en la misma recámara, me atreví a preguntarle qué había pasado, y lacónicamente me dijo que había peleado con Carlos Dávalos, y que no volvería a tratarlo, porque ése había resultado un puto. No averigüé más de aquel incidente; pero sentí que al escuchar a Guillermo condenarlo, me había ruborizado; que aquel desprecio, aquella ruptura violenta de una vieja amistad, se originaba justificadamente en la misma culpa siniestra de que yo me sabía el indefenso reo; y que ese destino de abyecta, súbita e irremediable segregación me aguardaba en la vida, en cuanto que cada uno de esos seres equilibrados y normales que tenían novias y acariciaban a las putas, fuera descubriendo que yo, en cambio, alentaba una sed angustiosa e irrefrenable por el beso de un héroe cinematográfico (80).

La clandestinidad, la humillación, y el ser descubierto transforman el goce en algo particularmente alienado. En el encuentro con el partner, el placer ya no está en juego como búsqueda, sino como escape. En la culminación, en el orgasmo, no está en juego el placer, sino una forma de fuga, al mismo tiempo que de afirmación: "espasmo sedante como una fuga y una compensación de mis frustraciones" (80); ¿¿de qué se fuga? ¿qué compensaciones requiere un joven cuyo talento es ampliamente reconocido por personalidades del momento?

Los perfiles acabados de los primeros amantes, de las primeras experiencias, se pierden en el torbellino numérico, cuando ya el cuerpo individual no cuenta sino la corporación, cuando los choferes se transforman en pasión. Ya ha conocido y ha despreciado el amor, ya ha fingido y se ha fisurado, y las curaciones han caído simbólicamente en el mismo sitio donde la academia se abre, en la oficina de Henríquez Ureña, condicionando el reconocimiento con la agresión (iqué enorme transgresión supone el hecho mismo de dejar las necesariamente sépticas cu- 
raciones en pudendas partes en la oficina de su mecenas! ¡ $\mathrm{Y}$ además contarlo!). A los veinte años ha deseado matar, ha aprendido a odiar, ha sido exhibido, estigmatizado y se ha creado un espacio y un nombre propio, que nada tiene que ver con las coordenadas simbólicas del otorgamiento de nombre, "Las chicas de Donceles".

Sus gustos se han fetichizado: Más que el individuo o el cuerpo, importa la nueva profesión, un chofer que conduce, esperará en la esquina de Brasil y Donceles. Más que el placer, uno se siente inclinado a pensar que importa un concurso en el que las hazañas tienen que ver con el volumen de un miembro erecto. No hay más nada que el número y el tamaño en erección tumefacta. Ninguna relación afectiva, ninguna relación más allá de la cama: ‘acaso vale algo ese otro que accede al acercamiento con quien es objeto de la homofobia? ¡hay que arrebatar el placer y desechar! Hay que despreciar a quien utiliza al paria despreciado para aliviarse.

La estatua de sal es también una visión de la cultura mexicana desde la óptica de la sexualidad. Allí aparecen Villaurrutia, Montenegro, Chucho Reyes, Torres Bodet, el cuerpo diplomático. La aristocracia aparece desde la adicción a una sexualidad vivida en un frenesí degradante. El centro de la ciudad se puebla con los nombres y los rostros de lo que no quiere ver la sociedad, de lo que niega. Hay toda una geografía afectiva que tiene asiento en una dirección precisa. La estatua de sal no es sólo una biografía, es el retrato apasionado de una ciudad que palpita de una manera desconocida, ${ }^{6}$ desde el sitio mismo de lo reprimido. El amor que no puede decir su nombre tiene una serie de representantes con nombre y apellido, ilustre, aristocrático. Es una sociedad que ha cambiado de nombre a favor de sobrenombres en muchas ocasiones infamantes y que responde a otras coordenadas dictadas por la lógica del ghetto.

En La estatua de sal se mezcla el ideal y la carne de una manera inédita; la inteligencia y un erotismo desembozado, que lo dice todo: el protagonista tiene el afán de mostrar otros principios, otras formas de ser, de vivir, de administrar la carrera, el estudio, la vida privada. Algo que no había imaginado la sociedad que existía.

\footnotetext{
${ }^{6}$ Novo nos dice que en la calle de Icazbalceta esquina con Altamirano vive Villaurrutia; en Donceles con Argentina, está el departamento de las chicas de Donceles; en Brasil 42, otro departamento de Novo; Antonio Adalid vive en Hidalgo 123.
} 
En La estatua de sal el cuerpo se transforma en corporación y se vuelve estatua. Solo convertido en una estatua el protagonista puede afrontar el apetito por la corporación. Sólo como una estatua puede vivir en una familia como un sitio en el que reina el silencio. Todo debe ser intuido y descubierto por un niño que vive aislado, solo. La desarticulación se siente en la familia. La abuela es la única que lo apoya de manera incondicional cuando debe presentar todas las materias en examen extraordinario. Una manera de revelarse en contra a las expectativas familiares. No sólo se va de paseo y no entra a las clases de la prepa, sino que abandona la carrera de abogado. Definitivamente la carrera de Novo no irá por el lado de la ley, sino apartado de ella y de los valores de la familia. A la postre ellos no pueden reprocharle nada porque es un joven brillante que ha empezado a publicar en los periódicos, a trabajar como maestro y a publicar libros como la antología del cuento mexicano que elabora por encargo de Henríquez Ureña. El incumplimiento de las expectativas lo transforma en algo diferente: no será un ser que se pliega a los deseos y valores del grupo familiar y social. A pesar de esta rebeldía mayúscula, nada le puede echar en cara su familia. Salvador Novo está a salvo de la reconvención. De la misma manera que no satisfará los deseos de dos hombres ricos, que le ofrecen su protección y su amor. Novo no responde a las expectativas de la familia y de la sociedad sino a los terrores de todos ellos: se convertirá en aquello que la madre no se atreve siquiera a nombrar, un afeminado, escribirá lo que en 1906 Eduardo Castrejón había reprobado inquisitorialmente en su novela-proceso Los cuarenta y uno.

¿Cómo está articulado el relato? Cada uno de los párrafos aborda un tema diferente. Pasa de sus aventuras, a la vida familiar, a la vida de sus amigos, al ghetto homosexual, y de nuevo a sus aventuras. El vigor de cada uno de los párrafos, la precisión de cada una de las escenas confiere al relato un ritmo de vértigo. No se detiene ante el duelo, no parece haber repercusiones de la indiferencia familiar, de la muerte de sus amigos. Narra cómo Clara, su amigo, se enamora de una loca, lo espera en su ventana, y entra en una espiral adictivo de cocaína, hasta que lo entierra su familia. Novo relata este episodio con distancia, sin permitirnos acceder a las resonancias afectivas que seguramente tuvo ese desenlace. Es como si no lo hubiera sentido. Sin embargo, no se puede poner en duda el hecho de que lo sintió hondamente. La prueba es que lo registra en el relato, donde sólo lo excepcional tiene cabida. 
Es preciso tener en cuenta de que se trata de una estatua de sal. No es solo un réprobo, sino un grupo de personas que transgreden las normas y que vuelven la cabeza para ver el destino de su ciudad, esos volteados.

\section{Un PINTOR LLAMADO FABRIZIO LUPO}

Publicada en 1952, y traducida al español en 1953, es importante considerar a Fabrizio Lupo dentro de la historia de la literatura mexicana homosexual. En primer lugar por la resonancia y el influjo que tuvo en la literatura mexicana. Por otro lado, porque su autor, Carlo Cóccioli, ${ }^{7}$ se estableció en nuestro país donde vivió medio siglo. ${ }^{8}$

Esta novela que se leyó mucho en México, al grado de ser considerada junto con El pozo de la soledad (1928) de Radclyffe Hall (18801943), como las novelas homosexuales por antonomasia, es una obra de juventud, publicada a los treinta y tres años; y que fue traducida cuando el autor tenía treinta y cuatro. ${ }^{9}$ En Fabrizio Lupo se construye la representación de la homosexualidad como un "caso", palabra que aparece en más de una ocasión en la novela.

\footnotetext{
${ }^{7}$ Italiano de nacimiento, Carlo Cóccioli nació en Livorno en 1920. A los treinta y tres años, en 1953, se estableció en México. Fue autor de 32 libros entre los que se cuentan El valle de Dios; Manuel, el mexicano; El guijarro blanco; Ambroise; A la luz del suelo; Yo, Cuaubtémoc; He encontrado al Dios de Israel; Hombre sin fuga; David, memorias del rey bíblico; Fiorello, réquiem para un perro; La casa del lago; La casa de Tacubaya; Los sexenios felices de Carlo Coccioli; Pequeño Karma... Murió en México el 5 de agosto de 2003. Cf. Notimex, "Muere el escritor Carlo Coccioli", en El Universal, 6 de agosto de 2003 .

${ }^{8}$ Habría que agregar que México fue también el país donde murió con el sentimiento de haber estado proscrito del reconocimiento oficial con la condecoración del Águila Azteca que sin duda merecía su labor literaria y periodística. Es preciso señalar que el autor modificó la ortografía de su nombre en México para que se pronunciara como esdrújula, razón suplementaria para incluirlo dentro de la literatura nacional.

${ }^{9}$ Vale la pena no olvidar este dato al recordar muchos otros de la estructura de la novela: el temperamento de los personajes, su rebeldía, la importancia que le otorgan a la fama, la necesidad del reconocimiento y el miedo cerval que desarrolla Lorenzo ante el rechazo homofóbico. Se trata de un mundo homosexual visto con los ojos de un joven, con toda la fogosidad, idealismo, teatralidad, impulsividad que la juventud puede tener.
} 
A principios de los años cincuenta, Fabrizio Lupo se suicida cuando contaba con veintiocho años, poco tiempo después de que Lorenzo se suicidara en París. Aquel con barbitúricos; éste en una motocicleta, arrojándose contra un autobús, final trágico para lo que antes se había perfilado como una pareja excepcional de dos pintores, que habían logrado una hazaña extraordinaria: establecerse como una pareja, abandonando la vida como una odisea de mingitorio (tales son las palabras de William, un amigo norteamericano de Fabrizio, desaparecido repentinamente — quizá como víctima de un crimen "pasional”). En la perspectiva de los homosexuales de los años cincuenta, encontrar un partenaire y la constitución de una pareja es el reto (aunque se podría señalar que este reto sigue vigente). Eso es lo único que a los ojos del joven pintor italiano, con una carrera que cuenta más de un centenar de pinturas y el reconocimiento de la crítica extranjera, lo puede redimir. Porque la homosexualidad, en los años cincuenta, es algo que debe ser "redimido”. En la argumentación en los tribunales eclesiásticos, y en términos generales, en la relación de homosexualidad con la iglesia, Fabrizio Lupo cobra una gran importancia. ${ }^{10}$ Fabrizio Lupo es una de las primeras obras que aborda la condena que pesa sobre los homosexuales en el catolicismo, ${ }^{11}$ cuyas etapas se pueden rastrear hasta la más reciente cinta la Mala educación (2004) de Pedro Almodóvar ${ }^{12}$ y que forzosamente han de pasar por la encíclica "Veritatis Splendor" (Esplendor de la Ver-

\footnotetext{
10 Otra novela mexicana homosexual, el Padre Prior (1971) de Mauricio González de la Garza (Nuevo Laredo, 1923-1995), lleva la narración a Santa María de la Resurrección, en Cuernavaca, para relatar la experiencia psicoanalítica del Padre Lemercier. Postales trucadas (2005) de José Joaquín Blanco (1951) describe una adolescencia en el convento y "Breve confesionario para el año 2000" es una lúcida reflexión sobre la explotación del pecado por la iglesia; Severino Salazar (1947-2005) coloca “También hay inviernos fértiles" en el seminario de Chihuahua.

${ }^{11} \mathrm{Y}$ en general en todas las religiones del Libro: judaísmo, Islam y cristianismo.

12 En la película de Almodóvar, el mal viene de la iglesia misma, una iglesia que pervierte cada una de las relaciones. Corrompe a Ignacio y después a su hermano; primero impide que se desarrolle el amor entre Ignacio y Enrique; luego lleva a Juan a asesinar a su hermano. El padre Manuel, en efecto, se complace en la corrupción. Los sacerdotes gozan allí donde los feligreses fracasan. La historia de los desencuentros de Ignacio y Enrique, contrasta con la eficacia corruptora del padre Manuel quien goza sexualmente; goza apartando a los niños que se aman; y goza también comprando a sus parejas, prostituyéndolos: Ignacio señala su primera relación como la primera vez que se vendió; su hermano Juan, también.
} 
dad). ${ }^{13}$ En la novela, los confesores de Fabrizio exhiben una postura inconsistente: Fabrizio señala que al tolerar la iglesia la promiscuidad y censurar el establecimiento de una relación homosexual (Fabrizio puede continuar siendo un buen católico si se confiesa y comulga después de sostener relaciones, no importaría ni el número ni la cantidad de partenaires), la iglesia muestra contradicciones dogmáticas no sólo frente a la homosexualidad sino con respecto a la sexualidad misma.

En contraste con esto, el dios de Fabrizio es un dios de amor que no puede excluir a los homosexuales que aman. Su concepción es clara y la expone con transparencia:

Creo en Dios, cuando pienso en ti; creo como jamás he sido capaz de creer; creo en un Dios bueno, poderoso, generoso, padre; un Dios que no amenaza, sino más bien nos exhorta; un Dios que se ha liberado de las frases de los hombres y se ha hecho sencillo y radiante: no Dios de amor, sino Amor; un Dios que para revelarme su terrible y maravillosa presencia no pretende, como ese sacerdote que se niega a absolverme, que te abandone... Porque tú eres la nobleza, la limpieza, el orden; eres aquel a quien he buscado noche y día a través de las calles de la ciudad; con una esperanza infatigable, no obstante los sufrimientos, las decepciones, las angustias, las locuras; con una certidumbre insensata, absurda, casi ridícula, que me hacía buscar y seguir buscando, y en la cual veo hoy una marca de ese Dios. Esta es, Lorenzo, la razón por la cual, suceda lo que suceda, cualesquiera que sean los lugares a los que mis días me destinen, podré decir para siempre que te amo (67).

Dios interviene en cada una de las acciones homosexuales, incluso en los avatares de la búsqueda de una pareja. Esta articulación de homosexualidad y catolicismo escandalizó en la época. En la sociedad de

\footnotetext{
${ }^{13} \mathrm{La}$ encíclica del sacerdote polaco repite en tres pasajes la condena; en el párrafo 81 dice: "La Iglesia, al enseñar la existencia de actos intrínsecamente malos, acoge la doctrina de la Sagrada Escritura. El apóstol Pablo afirma de modo categórico: “No os engañéis! Ni los impuros, ni los idólatras, ni los adúlteros, ni los afeminados, ni los homosexuales, ni los ladrones, ni los avaros, ni los borrachos, ni los ultrajadores, ni los rapaces heredarán el reino de Dios" (1 Co 6, 9-10)". Al polaco que cambió Polonia por América Latina; que compró la libertad de Polonia del comunismo, a cambio de acallar a los sacerdotes comprometidos con los pobres de América Latina, al intolerante que reinstituyó la Inquisición, a quien hizo innumerables llamados a la intolerancia ¿cómo se le llamaría? ¿Fariseo? ¿Demagogo?
} 
los cincuenta, y hasta la fecha, la religión no podía ser relacionada con la vileza. La postura fóbica de la iglesia que insiste en mantener una concepción tan arcaica en contra de los homosexuales, se basa en la figura de un dios repartidor de tierra, que manipula a su pueblo con el cebo de una tierrita: es necesario que su pueblo se reproduzca para convertir a sus criaturas en terratenientes (más ricos los feligreses; mayores los diezmos). Tal concepción mercantilista prevalece aún.

Los argumentos de Fabrizio son claros. En primer lugar, dios no condena, es un dios de amor que no puede censurar el amor entre dos hombres. En segundo lugar, la homosexualidad, como todo en el universo, ocurre por voluntad de la omnipotencia divina. Por lo tanto, condenar la homosexualidad equivale a poner en tela de juicio el misterio de los designios divinos; 3) quien condena son los sacerdotes; 4) es absurda la postura de la iglesia en cuanto a la absolución que perdona al homosexual que se arrepiente del pecado de lujuria (sin importar la promiscuidad) y condena a los homosexuales que perduran en una relación, porque esto resultaría desestabilizador para la familia.

Sin embargo, la felicidad y la unión amorosa se queda como espejismo inalcanzable. En realidad, Lorenzo no se atreve a mudarse con Fabrizio; tampoco quiere casarse. No puede asumir las consecuencias de ser homosexual socialmente. Su hermana alude a una chica que se convertiría en su esposa y con la que podría tener hijos. A pesar de haber encontrado una pareja, a pesar de la fidelidad que profesan y de la compatibilidad profesional, esta unión homosexual fracasa en su intento de asentarse socialmente. Fabrizio aduce la falta de una tradición que sostenga a la comunidad gay, a la que puedan los homosexuales referirse. Me permitiré hacer una cita larga para apreciar la precisión y pertinencia de los argumentos que esgrime el pintor:

El orden —dijo Fabrizio Lupo después de una larga pausa—, los que son como yo, deben irlo haciendo por sus propios medios, por etapas, a través de dificultades inimaginables, día tras día, y sin poder recurrir a una tradición, a una literatura, a un código, a un pasado. He aquí algo en lo que debería pensar el que arroja la piedra al empleadillo que seduce militares por detrás de los jardines del cuartel... Se les reprocha a muchos hombres como yo el no ser fieles a un amor único, el pasar de una aventura a otra, y yo mismo me he dejado llevar y he pronunciado palabras bastante ásperas. Pero a los que arrojan las piedras, a los que desprecian, a los que se burlan, ¿se les ha ocurrido alguna vez pensar 
que para gentes como nosotros no existe al comienzo ningún orden formal que nos asista, que nos salvaguarde, un orden, quiero decir, tal como matrimonio, asentimiento público, tutela jurídica y moral? ¿Se les ha ocurrido pensar, a esos que arrojan piedras, que para nosotros no existen precedentes válidos, ya que los únicos ejemplos son o demasiado elevados y desconocidos para que pueda invocárselos (de Platón a Leonardo de Vinci, y la tradición de Grecia, ya tan lejana...), o demasiado viles para que se recurra a ellos impunemente? Esta ausencia total de socorros exteriores hace de cada uno de nosotros un anarquista de después del diluvio; todo debe ser reconstruido, si se es capaz de reconstruir; es un imperativo cuya trágica urgencia experimenté yo mismo (que puedo, sin embargo, llamarme privilegiado) un día. He sentido que el desierto se extendía hasta las relaciones más íntimas; a los sentimientos, a las formas que debe imponerse a la pasión, a sus límites... Todo muchacho de veinte años que aborda a una muchacha sabe, con mayor o menor precisión, cómo se debe proceder en tal circunstancia; lo sabe incluso si es la primera vez que se acerca a ella, pues ha leído, ha oído, ha visto, ha observado todos los días de su vida. Por el contrario, nosotros no sabemos nada en absoluto. No solo debemos buscar el amor a través de dificultades de toda especie: prohibiciones, temores, angustias; pero asimismo decidir acerca de la forma de ese amor, construirlo e intentar después insertarlo en un orden. Es el más duro, el más doloroso de los fines. Un camino hecho de lágrimas y de compromisos y de renunciaciones; hecho sobre todo, de silencio y de espera. ¿Qué respondería mañana esa iglesia madre de los hombres a un hombre como Fabrizio Lupo? Porque Fabrizio Lupo, lo mismo que Alberto Ortognati, lo mismo que el empleadillo que seduce militares en la esquina de un cuartel, lo mismo que el adolescente que no sabe contener su turbación cuando se encuentra en la escalera con el hijo del vecino, lo mismo que esos hombres y mujeres innumerables que se ocultan o se exhiben, que pecan o que viven de acuerdo con la ley... Fabrizio Lupo, en suma, posee un alma. ¿Se ha dirigido hasta hoy día la iglesia a esa alma? Nosotros también tenemos derecho a una palabra (91-92).

Las preguntas han quedado sin respuesta. Por el contrario, aún están por venir las consecuencias de la vuelta al pasado que significó el último papado que restableció una nueva versión insidiosa de la inquisición, que acalló a sacerdotes progresistas y reforzó la condena a la homosexualidad (resulta desolador el hecho de que un joven como Wojtyla que padeció la persecución, se haya convertido en un adulto 
perseguidor y en un viejo obcecado: a la experiencia del totalitarismo, respondió con autoritarismo y acallamiento del diálogo).

Entre Fabrizio y Lorenzo, la relación que se establece es pasional, posesiva y desigual. Si Lorenzo subraya su necesidad de independencia y libertad, al tiempo que vive con su hermana, se puede atribuir parcialmente a la posesividad, los celos, la labilidad de los estados de humor de un joven pintor, arrogante, que se muestra demasiado seguro de sí mismo y consciente de su éxito. Un pintor que como artista reconocido aconseja al estudiante prometedor, activo, espontáneo, deportivo y seguro de sí mismo que es Lorenzo. Uno es el que aconseja, otro quien escucha; uno el que guía, el otro el que obedece; uno el experto; otro el que se inicia en el arte, en la homosexualidad, en la sociedad.

Entre Fabrizio y Lorenzo se produce un juego de poder en el que también se hace intervenir a la comunidad homosexual italiana y francesa. Los homosexuales italianos se muestran más que interesados por la apostura y juventud de Lorenzo, lo cual hace valer Lorenzo, inventando incluso un romance con Jaimito, para causar celos al pintor. Mientras Fabrizio subraya demasiado sus éxitos como pintor joven reconocido. Esos juegos tendrán sin duda su importancia en el pasaje al acto que se produce con el suicidio de los amantes, nueva edición corregida y aumentada — actualizada - de Romeo y Julieta. La diferencia es que en el presente caso no son los clanes rivales; sino la hostilidad de todos los clanes lo que impide el amor y la vida de la homosexualidad. Es la incapacidad de administrar la homosexualidad, la diversidad en una sociedad excluyente, moralista, persecutoria. Sin embargo, quien se opone al éxito de esta pareja no es sólo la sociedad y la iglesia, es también la comunidad homosexual:

Me siento aplastado por la casta de los Andrea Munari; los ángeles yacen con las alas rotas, y se ha perdido toda posibilidad de paraíso. Ese fango nos alcanza a todos, uno tras otro zozobramos en ese lodo inmundo; no somos más que unas putas. [...] Después, hay lo que nos concierne. Es decir, a los que, como nosotros, pacientes, sedientos de orden, ${ }^{14}$ no aceptan el renunciar sin combatir, los que se ponen ante Dios sin cansarse de plantearle la cuestión: "Respóndenos, ya que Tú eres responsable" (106-107).

\footnotetext{
${ }^{14}$ Esta constante invocación al orden por parte de Fabrizio Lupo debe ser considerada en la perspectiva de su pasión por dominar que ya se ha mencionado.
} 
En la soledad de la pareja, desprovistos de tradición y en un contexto masivamente hostil, se tiene que resolver los conflictos, al mismo tiempo que bregar con un frente muy amplio. No hay apoyo de ninguna clase por parte de nadie, ni siquiera por parte de los amigos más cercanos quienes no tienen poca responsabilidad en el desenlace suicida. Ellos son quienes con la envidia, con un apetito sexual sin límite, se convierten en adversarios de primera línea. Además, está la falta de seguridad en sí misma de la pareja. En la novela, cuentan más los obstáculos que hay para que una pareja homosexual logre establecerse, que las posibilidades:

Después un día, tuve conciencia de una realidad capaz de transformar mi vida: mi dolor nacía de un equívoco fundamental: yo no lloraba por lo que era, sino más bien por lo que una norma que no era la mía (y, por esto mismo, inaceptable por mi corazón y por mi razón) hubiese querido obligarme a ser. ¡Cuántos de mis semejantes habían acabado por ceder, ciega, furiosamente, al despotismo de ese equívoco! Amontonad una comunidad en un ghetto, habladle durante mil años de sus faltas, insinuad en el espíritu de sus miembros que están marcados por Dios, que son indignos de perdón, que la salvación se les niega; haced de ellos una imagen vergonzosa y difundidla, imponédsela a ellos mismos, a sus hijos; y lentamente, pero de una manera inexorable, su alma será desnaturalizada, acabarán por volverse semejantes a la imagen que de ellos habéis hecho; sobre esa imagen modelarán sus actos y sus pensamientos; acabarán por despreciarse tanto como vosotros los despreciáis; en una palabra, terminarán por daros la razón... Yo comprendí, un día, que nuestra condición era ésa. Entonces me dije: "Es preciso resistir a esa ola de embustes, vencer el equívoco, creer en nuestra nobleza original”. Jamás me he dicho, Lorenzo, que fuésemos mejores que los otros, sino que únicamente no éramos peores (109).

Los protagonistas de La estatua de sal y Fabrizio Lupo, comparten rasgos similares: Novo como Fabrizio es solitario, inteligente, ambos gustan de la lectura, en contraste con la poca disposición que poseen para los deportes. El gay que habla, el que se asume públicamente pertenece al primer grupo; el objeto sexual, que no habla, ni se asume, que goza de la consideración social, es deportista y hombre de acción. Así lo señala Fabrizio:

Leí mi primer libro cuando tenía diez años; una novela sacada a escon- 
didas de la biblioteca de mi padre; la lectura me apasionó como a otros los deportes, razón por la cual no tardé en organizarla (22).

Fabrizio y Salvador tienen un destino similar. Los libros aparecen como huida y como emblema. Los narradores construyen una imagen de un personaje interior, ensoñador. Es decir, necesariamente forzado por la hostilidad omnímoda, el gay puede ser creador de espacios interiores en los que se sienta bien. Si tiene talento, los inventa justamente por el oprobio que se le dirige en el ágora, en su casa. Este personaje rehuye en cambio las pruebas que ponen en juego lo físico (no me refiero a lo sexual, por supuesto).

Después de Freud, el relato típico de la vida del homosexual comienza con el nacimiento; se describe la relación con los padres; el apego a la madre. La biografía del protagonista se estructura como una historia sentimental en la que es preciso describir minuciosamente el camino hacia la homosexualidad: hacer el catálogo de los primeros deseos, las primeras manifestaciones del apartamiento de la norma, las primeras relaciones afectivas, las primeras relaciones sexuales. Es imperativo que los índices prematuros de la homosexualidad se produzcan en la temprana infancia, cuando el niño no tiene conciencia de una normatividad genérica rígida en la que se oponen los privilegios falocéntricos, con la integración varonil de lo femenino, supeditado e infamante. La homosexualidad surge como algo natural y desconocido: es algo a lo que el niño asiste con un acentuado interés, habida cuenta del aislamiento del niño y de que ignora todo de la vida sexual y de las combinaciones de prestigio y desprestigio que se desprende de la elección. Por lo tanto, si todo surge en un alma inocente, no habría una maldad o perversión imputables. Con el relato detallado de la infancia importa mostrar cómo la sensibilidad homosexual se ha establecido sólidamente antes de que se pueda acusar al sujeto de ser un enfermo sexual. La infancia se vuelve el sitio privilegiado de argumentación puesto que resulta imposible acusarla de inmoralidad, de retorcimiento. En todos los casos, se trata además de personajes que son niños ideales, es decir cumplen brillantemente con su deber en la escuela y son sobresalientes.

Citaré tres pasajes tomados de Fabrizio Lupo en que el narrador construye una imagen privilegiada del niño al tiempo que ganan terreno las inclinaciones homosexuales: 
a) Fabrizio muestra sus dotes como dibujante:

En clase, me revelaba bastante inteligente; decían de mí que tenía excepcionales dotes para el dibujo. Me acuerdo que un día me llevaron al circo; al volver a casa (tenía diez años), cogí mis lápices de colores y llevé a un papel las impresiones maravillosas que el espectáculo me había procurado. Nadie quiso creer que yo era el autor (22).

b) Fabrizio demuestra una sensibilidad excepcional:

Mi pubertad fue normal aunque precoz; descubrí por mí mismo el placer, y en la primera experiencia que hice, me puse de pronto a sollozar, pues creí que iba a morir (22).

c) Fabrizio utiliza sus atributos poco comunes:

yo le hablaba a Silvestro de mis lecturas [...] ¿Qué hubiera dicho de haber podido adivinar que yo no estaba allí sino para acechar el momento en que ella levantaba los cobertores? Pues entonces entreveía las piernas de Silvestro; y, al mirarlas, me sentía de repente otro, me exaltaba... (23)

El otro punto fundamental en el que se apoya la argumentación de Fabrizio Lupo, es en el amor como posibilidad para redimir al homosexual: es preciso pasar de la promiscuidad, a construcciones amorosas: era la época, que ahora parece tan remota, en que la heteronormatividad subrayaba el compromiso matrimonial hasta la separación por la muerte. A este respecto, Fabrizio afirma que "un hombre no debe ser juzgado por aquello que ama — dije lentamente—, sino por la manera cómo ama". La intensidad del amor, la pasión amorosa, la fidelidad como una construcción homoerótica contrasta con el contrato matrimonial heteronormativo, más del lado del ritual y que, además, desde los años sesenta entrará en crisis.

Desde entonces, aún antes de comprender mi verdadera índole, me sentía aterrado (éste es el término adecuado) por la nobleza, por la pureza de lo que experimentaba; y si aportaba a ese sentimiento cierto pudor, se debía tan sólo a que los otros, y de esto me daba cuenta, no habrían podido hacer otra cosa que deformarlo y envilecerlo (23). 
En las ondas profundas y azules, soberbiamente hendidas por la elevada proa que avanzaba, me parecía encontrar como un presagio de aventura: de esa aventura que iba, al fin, a sacarme del mundo de los otros y a conducirme al mío (aun bajo formas instintivas, la distinción se acentuaba). Entonces fue cuando, al levantar la cabeza, vi a un muchacho de mi edad sentado no lejos de mí sobre un montón de cadenas, con la nuca apoyada en el empalletado y las piernas extendidas.

Según supe más tarde, se llamaba Sergio (24).

La homosexualidad se representa como anagnórisis, se trata de un enlightement, del momento en que el sujeto se encuentra consigo mismo. Si el proceso se da de esta forma, el homosexual no es un pervertido sino que debe considerarse simplemente como un sujeto que oye una voz interior, y la sigue. No se trata de algo que viene de fuera sino de algo interior; por lo tanto queda desmontada la supuesta teoría de la corrupción de menores, del proselitismo, de la contaminación que tanto puede obsesionar a la sociedad como es el caso del destierro inmediato de los 41 para que no contaminen a una sociedad sana y robusta (con la perspectiva histórica podemos ironizar diciendo que ¡era tan sana que estaba a punto de la Revolución!) y se aleja de la alienación del mundo, es decir de la alienación heterosexual.

Por otro lado, Fabrizio Lupo hace un retrato de la comunidad gay de aquella época. En esa descripción cabría señalar la falta de conciencia grupal, y la profunda homofobia que dicta su pincel:

Todos saben que en toda las ciudades del mundo existe, más o menos abiertamente, una sociedad homosexual (el término de sociedad me repugna; no obstante me veo obligado a usarlo, ya que estoy hablando de algo concreto, real, y no sólo de un estado de espíritu, de una manera de ser...) Lo que, sin embargo, tal vez no sepan muchos, es el poder y la extensión de semejantes sociedades: quiero decir su exclusividad, la tiranía que de una manera o de otra acaban por ejercer en todos los dominios sobre quienes, aún en las formas más lejanas, entran en su categoría. Son corporaciones, verdaderas células, con sus costumbres, sus códigos, sus lugares de reunión, sus dignatarios; corporaciones cuyos miembros se consagran a determinadas profesiones con preferencia a otras, a aquellas que son más apropiadas a sus gustos, a sus ambiciones, a sus tradiciones, a su estado mental: actores, comediantes, anticuarios, decoradores, bailarines, toreros, sastres...; seres a los que la naturaleza ha dotado de una tendencia que lleva el sello de una belleza que es esencialmente mi- 
nuciosa, efímera, melodiosa, espiritual en el sentido más ligero de la palabra; seres alternativamente conscientes e inconscientes, representados siempre, sin embargo, por los más caracterizados de entre ellos; criaturas que, pese a su aversión por la mujer, son extremadamente afeminados, que se entregan a gestos propios de la mujer: gritos, contorsiones, cantos, monerías, juegos de palabras; que no saben crear, sino tan sólo refinar y luego destruir lo que han amenguado con su delicadeza; criaturas a quienes los heterosexuales desprecian (pero ellas se lo devuelven con creces); infortunados sobre los cuales siglos enteros de aversión y de persecuciones han obrado en profundidad, engendrado neurosis, sensibilidades paroxísticas, palideces repentinas, tics, temblores...; en una palabra, hombres-mujeres, que no constituyen el conjunto de los homosexuales, sino una pequeña parte de ellos, y que, sin embargo, los representan a todos a los ojos de la opinión; aún aquellos a los que el hombre de la calle alude cuando pronuncia desdeñosamente esa palabra tan horrible en su boca: pederasta; y que, sin embargo, en su mayor parte, no son culpables, ni tampoco despreciables; a los que se debe tan sólo compadecer, como víctimas que son, ya lo he dicho, de un pasado de persecuciones y de equívocos. Y sin embargo (a esto precisamente quería venir), ique terror no son capaces de suscitar esos dignatarios, esos representantes, en el alma de un muchacho de catorce o dieciséis años, cuando descubre de pronto que es su compañero de clase, y no su compañera, quien le inquieta! Un terror que nadie podrá imaginar jamás: es preciso haberlo sentido hasta el fondo para conocer sus formas y sus consecuencias. "Entonces, ¿quiere decir que yo soy como el anticuario X, como el actor Z?"; tal es la pregunta que se hace con horror el adolescente a quien la mirada de un muchacho que ha pasado por su lado casualmente ha dejado una emoción persistente y tierna... Y este terror es el que acaba con frecuencia por sumir al jovencito en esa neurosis que le convierte en fácil objeto de conquista, del mismo modo que el pájaro se encuentra empujado hacia las fauces de la serpiente por el horror mismo que experimenta (82-83).

Lo cual es una conducta muy generalizada entre los marginales (como la misoginia femenina; el racismo de indios y gente de color). Resulta imposible mezclarse con lo estigmatizado socialmente. Es preciso salvar el pellejo a toda costa aunque los semejantes se pierdan; hay que ser marginal pero excepcional; marginal pero diferente.

Fabrizio Lupo arremete contra la sociedad que lo censura, así como ataca a la comunidad gay. Sin embargo, esta novela logra definir con 
lucidez los puntos más urgentes de la agenda del homosexual en aquel momento en que debe comenzar por apartarse de las fuerzas que le obligan a actuar de manera diferente a lo que siente, a lo que cree. De allí proviene la soledad del gay, al mismo tiempo que el deber del gay. "Cuando se compromete uno en favor de una causa nada debe atemorizarnos, ¿`crees en mi causa?”. Si Fabrizio Lupo se presenta como caso, lo cual la vuelve ahora una novela caduca; también habla de una causa común lo cual la hace contemporánea.

En cuanto a la Iglesia:

No podéis - les diría - condenar a un hombre que ama según su naturaleza, dentro del orden y la pureza. Si lo hacéis, obligaréis a ese hombre a asociarse con otros hombres, y a invocar la venida de un Cristo, que sería el suyo. Vuestro Cristo no les atañería más, perdería todo derecho sobre su alma (91).

Tal como lo expone Fabrizio, el programa del homosexual y de la comunidad gay, es hacer tabla rasa de la sociedad y de sus valores. Inventar. Partir desde cero. Crear un espacio, normas propias, objetivos propios, independientemente de los dictados sociales. Crear algo nuevo. Tal es el objetivo de la sensibilidad diferente llamada homosexual. Fabrizio Lupo hace un llamado al compromiso por una causa. Su estrategia no sólo consiste en apartarse de la sociedad, sino también de la comunidad gay. El sujeto debe proponerse la creación de un espacio propio. Hacer tabla rasa es el primero de los imperativos y al mismo tiempo es lo único que puede "salvar" al homosexual. Este debe además establecer un compromiso con el otro, otro que se elabora como pareja, y también hacer un compromiso con una causa colectiva. Como puede apreciarse, Fabrizio Lupo logra definir el compromiso como una forma de vida individual y colectiva.

Antes de suicidarse, Fabrizio Lupo quema todas sus pertenencias y sus cuadros. Pone a salvo el manuscrito. Lo único que deja es una demanda: es preciso que a través de la escritura, de la novela, cuyo narratario sería la comunidad homosexual, se sepa de Fabrizio y Leonardo, de los obstáculos que no pudieron superar y de su suicidio. Lo importante es mantener la esperanza en otras posibilidades de realización de la pareja. Una esperanza que se configura como relación afectiva. Frente a ese propósito, todo se desvanece. Fabrizio es también un 
filántropo que deja una herencia a la comunidad gay. De acuerdo con los planteamientos ficcionales, Fabrizio destruye una obra plástica que lo colocaría dentro de la historia de la pintura, para posicionarse dentro de la historia de la cultura gay. Su vida es ejemplar tanto por el fracaso que significa su suicidio, así como por sus resonantes logros como lo es el mantenimiento y transmisión de una esperanza. Paralelamente, la derrota de Fabrizio, la de Fabrizio y Lorenzo, significa también el fracaso de la comunidad homosexual de su momento.

Cuando alguien se suicida mata a alguien a través de ese yo: si en el caso de Lorenzo se trata de Fabrizio y de la homofobia que lo abruma, en el de Fabrizio, más allá del gesto romántico de reunión amorosa, su acto quiere acabar con la sociedad homófoba, con la intolerancia de la sociedad gay del momento.

BiBLIOGRAFÍA

Acero, Rosa María. Novo ante Novo: un novisimo personaje homosexual. Madrid: Editorial Pliegos, 2003.

Castrejón, Eduardo A. Los cuarenta y uno: novela crítico social. México: 1906 (Ejemplar en la Biblioteca Nacional: M863.4/CASTRE.c.)

"Cóccioli, Carlo", en Diccionario de escritores mexicanos. Tomo I. México: Instituto de Investigaciones Filológicas, Centro de Estudios Literarios. México: 1988, 374-377.

- Fabrizio Lupo. Trad. del francés, Aurelio Garzón del Camino. México: Compañía General de Ediciones, 1957.

http://www.geocities.com/fabriziolupo.geo/01 pagina002.html\#uno hoja de homenaje a Carlo Cóccioli; edición en línea de Fabrizio Lupo.

Novo, Salvador. La vida en México en el periodo presidencial de Manuel Avila Camacho. Compilación y nota preliminar por José Emilio $\mathrm{Pa}-$ checo. México: Instituto Nacional de Antropología e Historia, 1994.

- La estatua de sal. México: Consejo Nacional para la Cultura y las Artes, 1998.

SCHNeIder, Luis Mario. "El tema homosexual en la nueva narrativa mexicana”, en Ensayo literario mexicano. Selección de John S. Brushwood, Evodio Escalante, Hernán Lara Zavala y Federico Patán. México: Universidad Nacional Autónoma de México / Universidad Veracruzana / Editorial Aldus, 2001. 